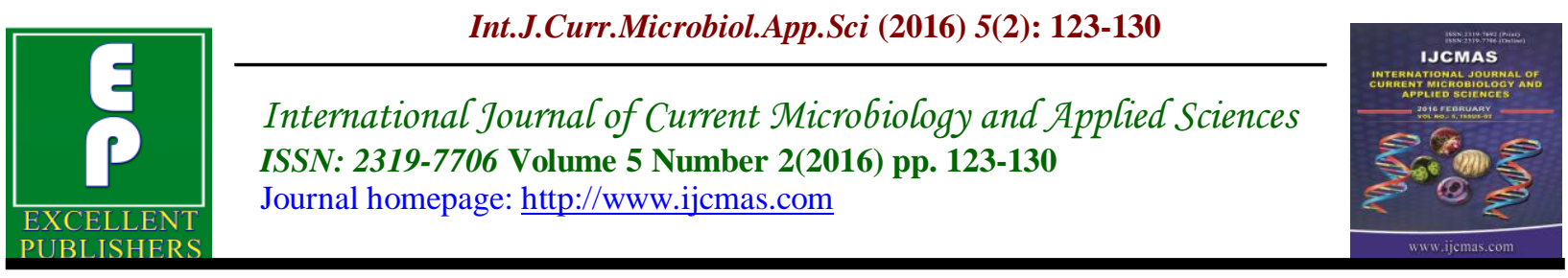

Case Study

doi: http://dx.doi.org/10.20546/ijcmas.2016.502.014

\title{
Polyparasitism-An Emerging Cause of Diarrhea: A Case Report
}

\author{
Suwarna Pawar*, Mayuri Bhise, K.V.Ingole, N.K.Shaikh, Rashmi Bawane \\ Department of Microbiology, Dr V.M.Govt Medical College, Solapur, India \\ *Corresponding author
}

\begin{abstract}
A B S T R A C T
Keywords

Polyparasitism,

Diarrhea,

non-endemic

parasitic

infestations

Article Info

Accepted:

12 January 2015

Available Online:

10, February 2016

Intestinal parasitic infestations are major public health problems in developing countries like India. Co infection with two or more parasitic infections further worsens the situation. In this report, we are discussing a case of 12 year old girl, who was admitted in Pediatric inpatient department of our hospital, with chief complaints of acute abdomen, loose stools, crampy abdomen and vomiting after eating pork meat. On routine stool examination trophozoite of B.coli, eggs and segments of $T$. solium, unfertilised eggs of Ascaris lumbricoides and cyst of Giardia lamblia \& Entamoeba histolytica were observed. Patient was started on Albendazole therapy immediately after the stool routine examination to which she responded well and discharged after 20 days. This study reflects that it is important to consider multiple and non-endemic parasitic infestations in low socioeconomic population as it can be a cause of diarrhea. These parasitic infestations can be prevented by proper education of hygienic habits, sanitation and regular deworming exercise especially at primary school level.
\end{abstract}

\section{Introduction}

Intestinal parasitic infestations are major public health problems in developing countries like India. Co infection with two or more parasitic infections further worsens the situation ${ }^{1}$. Poor personal and environmental hygiene, overcrowding, lack of access to clean drinking water and varied climatic factors are the risk factors for such infections ${ }^{2}$. Polyparasitism increases the risk of morbidity like growth retardation, anemia, decreased physical performance and impaired cognition. Studies have shown adequate antiparasitic treatment improves nutritional status and growth in children ${ }^{1}$.

Parasitic infections, caused by intestinal protozoan and helminthes are more prevalent in the poorest sections of the population and re-infection in endemic areas is continuous ${ }^{3}$.

Balantidium coli are only parasitic ciliate and infrequent pathogen for human beings ${ }^{4}$. Pig is the most common reservoir of this infection. In all, there have been about 50 species described. The species found in pigs, Balantidium suis, is likely identical to $B$. coli from humans. Other species have been isolated from guinea pigs (Balantidium caviae), cockroaches (Balantidium blattarum), fish, birds, and amphibian ${ }^{5}$. The humans acquire this infection by ingestion of food and water contaminated by pig faeces. The infection primarily affects the 
colon and presents as mild abdominal discomfort to severe dysentery. It commonly infects the immuno-compromised and malnourished host in which infection can be fatal $^{4}$. This is the rare case of diarrhea which is caused due to $B$. coli.

Taenia sagginata and Taenia solium are two medically important species of Genus Taenia ${ }^{6}$. T. solium is second most common cause of intracranial space occupying lesions after tuberculosis ${ }^{7}$. The demonstration of egg or segments of parasite in stool is considered for diagnosis of this infection. The eggs of Taenia species are bile stained. Both the species can be differentiated by number of proglottids which are expelled in stool. In case of Taenia solium proglotids are expelled in chains of 5 or 6 while in case of Taenia saginata it expelled singly. Man acquires infection by eating raw or undercooked pork containing cysticercus cellulosae or by ingesting the eggs with contaminated water and food ${ }^{6}$.

According to the WHO, 980 million people are infected with intestinal roundworm Ascaris lumbricoides. It has worldwide distribution, being especially prevalent in tropics, such as India, China and Southeast Asia $^{3}$. The infection is highest among malnourished people residing in developing countries.

Man acquires infection by ingestion of food, water or raw vegetables contaminated with embryonated eggs ${ }^{8}$. A.lumbricoides, though less harmful to the gastrointestinal mucosa, has migratory behavior and can cause obstruction in the gastrointestinal lumen ${ }^{9}$. The adult worm also affects the nutritional status of the host leading to malnutrition and night blindness due to Vitamin A deficiency. The long term effect of the malnutrition can lead to growth retardation ${ }^{8}$.
Giardia lamblia is a flagellate of worldwide distribution. It is the most common flagellate of intestinal tract, causing Giardiasis. Most common symptom of Giardiasis is diarrhea ${ }^{10}$. It is well documented that in developing countries, infections are associated with poor sanitary conditions, poor water quality and overcrowding $^{11}$.In developing countries, there is a very high prevalence and incidence of infection and data suggest that long-term growth retardation can result from chronic giardiasis $^{12}$.

Entamoeba histolytica is the third leading parasitic cause of death in the developing countries, infecting more than $10 \%$ of world's population $^{13}$. It is endemic in India and affects all age groups. Humans are affected through food and water contaminated with the cysts of $E$. histolytica due to feces, flies or unwashed hands of food handlers ${ }^{14}$.

Here, we are presenting a case report of a 12 year old girl who was admitted in our hospital with complaints suggesting gastrointestinal infection. On investigation, it revealed a rare combination of infection with multiple parasites which included $B$. coli, Taenia solium, Ascariasis lumbricoides, E.histolytica and G. lamblia.

Case Report: A 12 year old girl, was brought to pediatric OPD with complaints of fever, abdominal pain, loose stools and not accepting feeds since $2-3$ days. There was no history of vomiting. There was history of pica. The patient had mixed diet. . She has history of eating pork meat. She was admitted to pediatric inpatient department.

On examination, she was irritable, pale, lethargic and cachexic with low grade fever not associated with chills or rigor. General condition was poor. Her eyes were dry and 
platynychia was noted. Skin pinch retracted slowly which was suggestive of moderate dehydration. Pulse was 126 beats/ min; respiratory rate was $20 / \mathrm{min} \&$ blood pressure 100/70 $\mathrm{mm} \mathrm{Hg}$.

Anthropometrically, height was $16 \mathrm{~cm}$, weight $13 \mathrm{~kg}$, head circumference $45 \mathrm{~cm}$, chest circumference $49 \mathrm{~cm}$, mid-arm circumference $11 \mathrm{~cm}$, upper segment: lower segment 54:62.

On blood investigations showed microcytic hypochromic anaemia (hemoglobin was $9.2 \mathrm{~g} / \mathrm{dl})$, low total protein $(4.6 \mathrm{~g} / \mathrm{dl})$ and albumin $(2 \mathrm{~g} / \mathrm{dl})$ was noted. Total leukocyte count was $9200 / \mathrm{mm}^{3}$ with differential count of Polymorphs-62, Lymphocyte-26, Eosinophils- 11 \& Basophil-1. Serology for HIV antibodies was non reactive.

The stool sample of the patient was sent to microbiology department for further examination.

\section{Macroscopic Examination}

Grossly the stool was yellowish green, semisolid, foul smelling. Segments of tapeworm were detected macroscopically. These segments are expelled in chains of 510 in number.

\section{Microscopic Examination}

Saline and Iodine mounts were prepared and examined. On saline mount motile trophozoite of B.coli was detected. Trophozoite was oval in shape, 30-300 X 30-100 $\mu \mathrm{m}$ in size, cilia was present, V shaped cytostome was present, nucleus and vacuoles were also present ${ }^{4}$. Trophozoite of B. coli was also demonstrated in iodine mount.

There were also eggs of Taenia solium which were bile stained round, 35- $40 \mu \mathrm{m}$ in size, with three pairs of hooklets and these were non acid-fast ${ }^{7}$.

Unfertillised eggs of Ascariasis lumbricodes were also demonstrated in Saline and iodine mount. These were oval in shape and measured around 60-75 $\mu \mathrm{m}$ in length and $40-50 \mu \mathrm{m}$ in breadth. They were bile stained and brown in color. They had a small atrophied ovum and a thin shell within an irregular coating of albumin ${ }^{8}$.

Abundant cysts of Giardia lamblia were also observed in saline and iodine mount. These were about $8 \mu \mathrm{mX} 12 \mu \mathrm{m}$ in size oval in shape. It has two pairs of nuclei which were seen on both the sides of axostyle and also the abundant cysts of Entamoeba histolytica were detected which were round in shape, $12 \mu \mathrm{m}$ x $20 \mu \mathrm{m}$ in size 9 .

Bacterial culture was negative.

Repeat samples were collected on day 3 and day 4, after starting treatment, which showed marked decrease in parasites.

\section{Treatment}

She was earlier started with Amikacin as clinicians were suspected a bacillary cause of diarrhoea, as patient had history of fever. After reports of stool microscopy she was immediately treated with Albendazole 400 mg HS at night the health of the child improved after 3 days Albendazole therapy She was further started on Metronidazole therapy for 14 days. After the course of antiparasitic therapy diarrhea stopped and child's appetite was improved. Stool microscopy was repeated twice after two weeks which did not revealed any ova or cyst. She was discharged after 20 days.

B.coli infection is found world-wide. This infection is most prevalent in South and Central America, China, Iran, Indonesia, 
Philippines, New Guinea and Pacific Islands ${ }^{15}$. Very few case reports on Balantidium infection have been reported from India. Extra intestinal infections of B.coli include the liver, lung and genitourinary tract. Four case reports of urinary balantidiasis have been reported (one from Italy, one from USA and two from India) ${ }^{16}$. One case report of Balantidium coli-induced pulmonary haemorrhage with iron deficiency has been reported $^{17}$. Intestinal case report on "Balantidium coli in an HIV-infected patient with chronic diarrhoea" has been reported by Cermano et $\mathrm{al}^{18}$.

Figure.1 Trophozoite of $B$. coli on Iodine Mount

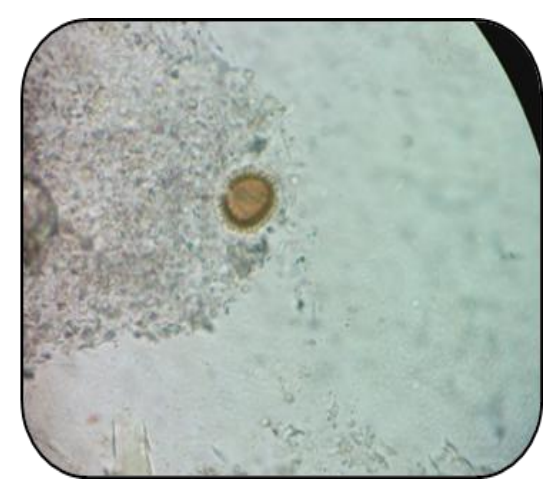

Figure.2 Egg of Taenia Solium in Saline Mount

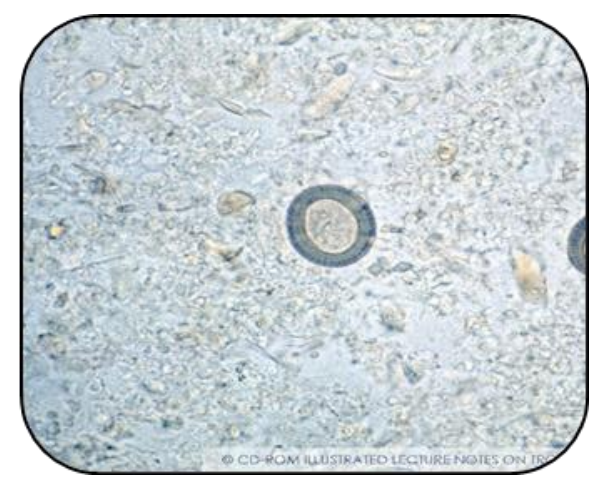

Figure.3 Unfertilised Egg of A. lumbricoides in Iodine Mount

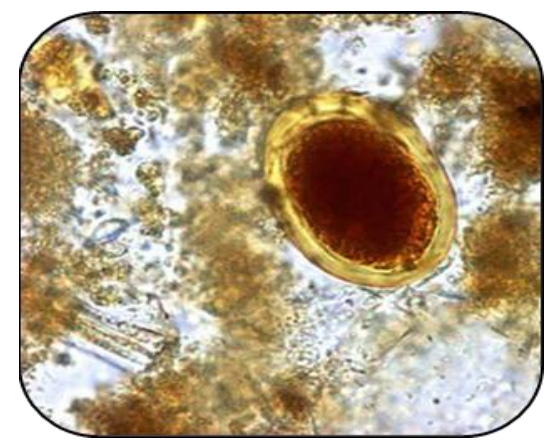


Figure.4 Cyst of G. lamblia in Iodine Mount

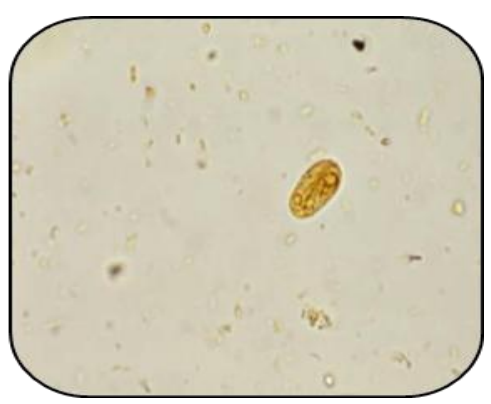

Figure.5 Cyst of E. histolytica in Iodine Mount

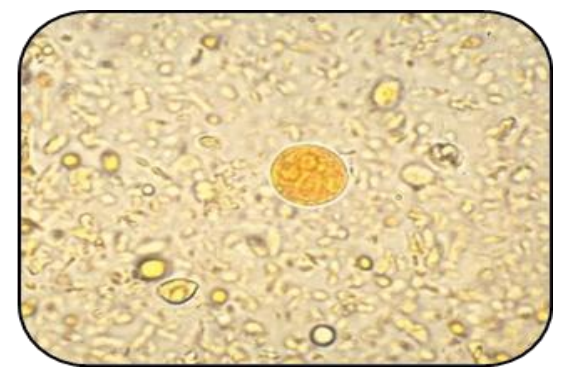

Figure.6 Segments of T. solium (10X)

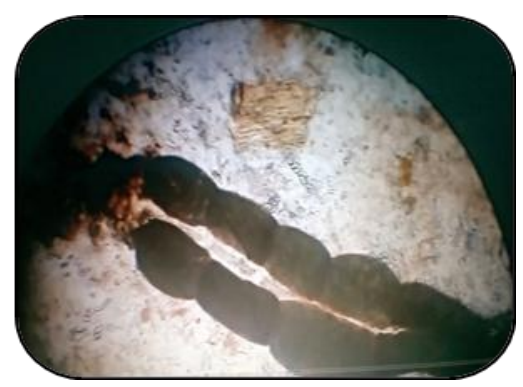

Cysticercosis caused by Cysticercus cellulosae, a larval stage of the tapeworm Taenia solium, is a major public health problem, especially in the developing world $^{19}$. The commonest form is neurocysticercosis (NCC) and this is the single most common cause of epilepsy in developing countries. Disseminated cysticercosis occurring as a result of widespread invasion of the larval form into various tissues is a rare manifestation of cysticercosis. Fewer than 60 cases of disseminated infection have been reported worldwide $^{19}$. It is common in communities where people consume undercooked pork although the proportion of pork eaters among Indian patients is low, an unusual feature of the disease in our country ${ }^{20}$. In a study performed by Girotra et al observed that Only $34 \%$ of the NCC patients ate pork. In a study from North India, 26\% patients ate pork $^{21}$. In present study the patient has history of eating pork meat. 
Ascaris lumbricoides is an intestinal nematode (roundworm); it is one of the most common helminthic human infections worldwide. It is estimated that, over half of the adolescents in India are infested with round worms. A number of features account for its high prevalence including a ubiquitous distribution, the durability of eggs under a variety of environmental conditions, and poor socioeconomic conditions that facilitate its spread $^{22}$. Ascaris infection produced a remarkable and significant adverse effect on the weight gain, skin and mouth condition of the infected children and also to the nutritional deficiencies in children. Ascaris infection leads to delimitating effect on the growth, and developmental process of the children who are the victims of these intestinal parasites $^{23}$.

Giardia lamblia is a protozoan parasite which is an important cause of diarrhea in India. In addition to diarrhea, it can also lead to malnutrition and cognitive deficits in children $^{24}$.

Entamoeba histolytica, associated with high morbidity and mortality continues to be a major public health problem throughout the world. Asymptomatic individuals account for almost $90 \%$ of the infections. Poverty, ignorance, overcrowding, poor sanitation and malnutrition favor transmission and increased disease burden ${ }^{22}$.

Among the conditions influencing the development of these infections are poor sanitary conditions, lowering resistance of the host, population explosion, inadequate control of vectors and infection of reservoirs, increased migration, and military operation and travelling around the world ${ }^{3}$.

The parasitic infections make a significant contribution to the development of nutritional deficiencies in children. So elimination of intestinal parasites in children from developing countries is needed.

\section{Conclusion}

Parasitic infections though not life threatening, but chronic infections can impair physical and mental growth of children and general development of individuals. Parasitic infections can lead to poor cognitive performance in children. Among these multiple parasites except Balantidium coli all the other parasites transmits by food and leads to food borne infection. These diseases are preventable by following simple preventive measures. These preventive measures include 1) personal hygiene 2) Meat hygiene which extends from selection of animals for slaughtering to cooking of meat at consumption level. 3) Proper purification of water. 4) Educating people regarding the burden, modes of transmission, personal hygiene, environmental sanitation, meat processing.

\section{References}

1. Rudresh S.M, Basavaraj, Shylaja P. \& Ravi G. S., 2015. Multiple Parasitic Infestations with Fasciolopsis Buski, Entamoeba Coli and Ascaris Lumbricoides in a Migrant: A Case Report. International Journal of Current Medical And Applied Sciences. 6(2): 122-123.

2. Sunil H S, Gandhi BP, Avinash B, Devi G, Sudhir U., 2014. Parasitic zoo of Fasciolopsis buski, Gastrodiscoides hominis, Giardiasis intestinalis, and Entamoeba histolytica. J. Indian Acad Clin Med. 15(3-4):240-2

3. Fernanda B. MORRONE, Juliana A. CARNEIRO, Cristine dos REIS, Cibele M. CARDOZO, Caroline UBAL \& Geraldo A. DE CARLI., 
2004. Study of Enteroparasites infection frequency and chemotherapeutic agents used in pediatric patients in a community living in porto alegre, rs, brazil. Rev. Inst. Med. trop. S. Paulo. 46(2):7780.

4. Poudyal N, Baral R, Gyawali N, Gurung R, Amatya R., 2011. Intestinal infection with multiple parasites including Balantidium coli. Health Renaissance. 9 (1) : 45-46.

5. Baker, J. R. Parasitic protozoa., 1973. Hutchinson University Library, London, United Kingdom.

6. D.R.Arora, B. Arora., 2007. Cestodes or Tapeworms. Medical Parasitology, 2 nd edition. CBS Publishers and Distributors, New Delhi. 119-124.

7. Subhash Chandra Parija., 2013. Cestodes: Cyclophyllidean Tapeworms Taenia, Echinococcus, Hymenolepis and Dypylidium. Textbook of medical parasitology: Protozoology and helminthology, 4th edn, All India Publishers and Distributors, New Delhi.189-200.

8. D.R.Arora, B. Arora., 2007. Nematodes. Medical Parasitology, 2 nd edition, CBS Publishers and Distributors, New Delhi. 179-183.

9. Prajapati B.K., Rajput A. H., Shah A.D., and Kadam M.T., 2012. "Case report: A case of Polyparasitism in a 10 year old child." Indian Journal of Basic \& Applied Medical Research. 1(3):239-241.

10. Michael J. Cuomo, Lawrence B. Noel, Daryl B. White, DIAGNOSING MEDICAL PARASITES: A Public Health Officers Guide to Assisting Laboratory and Medical Officers

11. Espelage, W., Heiden, M., Stark, K., Alpers,K. 2010. Characteristics and risk factors for symptomatic Giardia infection in Germany. BMC Public
Health, 10: 41.

12. Adam, R. 2001. Biology of Giardia lamblia. Clin. Microbiol. Rev., 14(3): 447-475.

13. D.R.Arora , B. Arora., , 2007. Amoebae.Medical Parasitology, 2 nd edition, CBS Publishers and Distributors, New Delhi. 19-36.

14. Montes, M., Sawhey, C., Barros, N., 2010. Strongyloides stercoralis: there but not seen. Curr. Opin. Infect. Dis.,23(5): 500504.

15. Subhash Chandra Parija., 2013. The ciliate protozoa Balantidium. Textbook of medical parasitology: Protozoology and helminthology, 4th edn, All India Publishers and Distributors, New Delhi.171-175

16. T Karuna, Sagar Khadanga.,2014. A rare case of urinary balantidiasis in an elderly renal failure patient, 4 (1) : 47-49.

17. Koopowitz A, Smith P, Rensburg N van, Rudman A., 2010. Balantidium coliinduced pulmonary haemorrhage with iron deficiency S Afr Med J . 100: 534-536.

18. Cermeño, Julman Rosiris ${ }^{a}$; Hernández de Cuesta, Isabel $^{\text {a; }}$ Uzcátegui, Orlando ${ }^{\mathrm{a}}$; Páez, Javier ${ }^{\mathrm{a}}$; Rivera, Mario ${ }^{\mathrm{b}}$; Baliachi, Norka ${ }^{\mathrm{c}}$., 2003. Balantidium coli in an HIV-infected patient with chronic diarrhea. 17 (6) 941-942.

19. Bern C, Garcia HH, Evans C, Gonzalez $\mathrm{AE}$, Verastegui M, Tsang VC, et al., 1999. Magnitude of the disease burden from neurocysticercosis in a developing country. Clin Infect Dis.29:1203-9.

20. Rajshekhar V. Epidemiology of taenia solium taeniasis/ cysticercosis in India and Nepal., 2005. Southeast Asian J Trop Med.Public Health. 35:247-51.

21. Girotra M, Gera C, Ryfka Abraham R, 
Kaur P, Gauba R, Singh Y, Pandian J., 2014. Risk factors for neurocysticercosis: A study from Northwest India. CHRISMED Journal of Health and Research. 1(1): 21-24.

22. Monthly Newsletter of National Centre for Disease Control., 2009. Directorate General of Health Services, Government of India . CD Alert Food Borne Dis 13:1-12.
23. Adekunle, Lola. Intestinal parasites and nutritional status of Nigerian children. Afr. J. Biomed. Res. 5; 115- 119.

24. Praveen Kulkarni, D Sunil Kumar., 2014. Food-borne parasitic infestations in India: Need for attention towards unattended International Journal of Health \& Allied Sciences. 3(4).

\section{How to cite this article:}

Suwarna Pawar, Mayuri Bhise, K.V.Ingole, N.K.Shaikh, Rashmi Bawane. 2016. Polyparasitism-An Emerging Cause of Diarrhea: A Case Report. Int.J.Curr.Microbiol.App.Sci. 5(2): 123-130. doi: http://dx.doi.org/10.20546/ijcmas.2016.502.014 